\title{
Taman Pintar Dengan Pendekatan Arsitektur Ekologi Di MATARAM
}

\author{
Sabriyan Arsyi Rahman, Edi Pramono Singgih, Wiwik Setyaningsih \\ Program Studi Arsitektur \\ Universitas Sebelas Maret Surakarta \\ Email : sabriyan_arsyi94@yahoo.co.id
}

\begin{abstract}
Mataram City is the capital of West Nusa Tenggara Province. Existing issues in the Mataram City becoming the background of planning and designing Taman Pintar in Mataram based on Ecology Architecture, as for instances, the increasing interest of science and technology, the principle of recreational education which can increase the public interest, the government's plan to develop new tourist destinations with educational theme, Mataram City as the educational center of West Nusa Tenggara Province and provides insights the public about preserving the environment. The problem of the design is implement the concept of ecology with a focus on environmental adaptation, conservation ecological element and Taman Pintar in an effort to preserve nature. The purpose of this design is to get the design and building of Taman Pintar as a place of recreational education on science and technology with environment by implementing the concept of Ecology Architecture. The method used is a method of designing architecture based on Ecology Architecture approach. The results obtained are the design of Taman Pintar based on Ecology Architecture approach that is applied to environmental adaptation and conservation ecological element, that is the use of variety form and the height difference to accentuated dynamic and recreative impression, site zonification affected by site existing, the arrangement of form and facade building affected by climatology and noise in site factor, the use of material is minimize eksploitation of natural materials, utilizing natural potensial for alternative energy, minimize the wasting product by recycle and sewage treatment that can be used in Taman Pintar's site.
\end{abstract}

Keywords: conservation ecological element, Ecology Architecture, Environmental Adaptation, Recretional Education, Taman Pintar

\section{PENDAHULUAN}

Ilmu pengetahuan dan teknologi merupakan sesuatu yang akan terus berkembang dari waktu ke waktu mengikuti perkembangan kebudayaan dan pemikiran manusia.

Indonesia menjadikan ilmu pengetahuan dan teknologi sebagai hal yang penting dalam memajukan wawasan masyarakatnya, hal tersebut tercermin dalam UUD 1945 amandemen ke-4 pasal $28 \mathrm{C}$ ayat (1) yang berbunyi "setiap orang berhak mengembangkan diri melalui pemenuhan kebutuhan dasarnya, berhak mendapatkan pendidikan, dan memperoleh manfaat dari Iptek, seni, dan budaya demi meningkatkan kualitas hidupnya dan demi kesejahteraan umat manusia".

Salah satu cara dalam meningkatkan minat masyarakat terhadap ilmu pengetahuan dan teknologi yaitu penyampaian materi menggunakan metode yang interaktif, menghibur serta menarik terutama bagi anakanak dan remaja.

Taman Pintar hadir sebagai wadah kegiatan yang mengangkat konsep rekreasi edukatif sebagai metode yang digunakan untuk mewujudkan hal tersebut, sehingga dapat membantu pengunjung terutama dari kalangan pelajar untuk meningkatkan minatnya dalam mendapatkan ilmu pengetahuan.

Berdasarkan rencana pembangunan setempat, Pemerintah Provinsi Nusa Tenggara Barat berencana merancang science park di Kota Mataram seperti Taman Pintar di Yogyakarta, sehingga masyarakat yang datang bisa mendapatkan bermacam hal, baik ilmu pengetahuan, kekayaan seni dan budaya lokal. Science Park ini juga dapat berfungsi juga sebagai ruang terbuka hijau di Kota Mataram (mataram.antaranews.com).

Berdasarkan pada Rencana Pembangunan Jangka Menengah Kota Mataram tahun 2011-2015 (mataramkota.go.id), pertumbuhan penduduk 
di Kota Mataram akan semakin meningkat, mengingat bahwa Kota Mataram merupakan ibukota provinsi, pusat pemerintahan, pendidikan serta perdagangan dan jasa. Hal tersebut akan mempengaruhi pembangunan di Kota Mataram semakin meningkat, dan mengakibatkan lahan terbuka hijau serta ruang publik semakin berkurang di Kota Mataram.

Perancangan Taman Pintar di Kota Mataram bertujuan untuk meningkatkan pemahaman masyarakat terhadap ilmu pengetahuan dan teknologi serta dapat menikmati ruang terbuka hijau kota yang akan memotivasi masyarakat untuk menjaga lingkungan sekitar.

\section{METODE}

Kegiatan dan peruangan pada Taman Pintar menerapkan konsep rekreasi edukasi yang diaplikasikan dalam memberikan variasi ketinggian pada bentuk dan tampilan serta sirkulasi.

Taman Pintar yang direncanakan menerapkan konsep Arsitektur Ekologi yang fokus pada adaptasi lingkungan dan konservasi unsur ekologi.

Adaptasi lingkungan diterapkan pada gubahan dan tata massa yang dipengaruhi pergerakan angin untuk mengoptimalkan penghawaan baik pada kawasan maupun pada bangunan, serta tampilan bangunan yang diterapkan berdasarkan arah pergerakan matahari, sehingga tampilan bangunan yang terkena radiasi matahari langsung diberikan barrier dan secondary skin. pada :

Konservasi unsur ekologi diterapkan

1. Air : pengolahan grey water sehingga dapat dimanfaatkan kembali serta meminimalisir penggunaan air tanah.

2. Udara : meminimalisir penghawaan buatan dengan mengoptimalkan pergerakan angin menuju tapak.

3. Tanah/material : material yang digunakan meminimalkan eksploitasi bahan alam serta pengolahan kembali limbah sampah.

4. Api/energi : efisiensi energi dihasilkan dengan mengoptimalkan penghawaan dan pencahayaan alami serta memanfaatkan energi alam.

\section{ANALISIS}

\subsection{Analisis Pendekatan Arsitektur Ekologi}

Analisis pendekatan Arsitektur Ekologi dilakukan dengan tujuan untuk mendapatkan pengaruh Arsitektur Ekologi terhadap desain.

Berdasarkan pada Frick (1998), unsurunsur Arsitektur Ekologi yang perlu diperhatikan terdiri dari udara, air, tanah/bumi serta api/energi.

Aspek-aspek yang perlu diperhatikan dalam perancangan berbasis Arsitektur Ekologi berdasarkan Yuliani (2014) yaitu :

1. Apresiasi budaya masyarakat lokal

2. Pemanfaatan potensi lingkungan

3. Pengendalian kendala yang dihadapi di lingkungan

4. Adaptasi iklim setempat

5. Efisiensi dan konservasi energi

6. Pemilihan teknologi yang bijaksana

\subsection{Analisis Penentuan Tapak}

Tujuan : lokasi yang sesuai dengan fungsi Taman Pintar.

Dasar pertimbangan yaitu :

1. Tapak terletak di Kawasan Ampenan, bukan merupakan kawasan lindung dan bisa didirikan bangunan sesuai dengan peraturan pemerintah.

2. Tapak merupakan kawasan yang dapat digunakan untuk kegiatan rekreasi/wisata serta pendidikan.

3. Akses menuju lokasi mudah dijangkau dengan kendaraan umum maupun pribadi.

4. Memiliki potensi yang dapat mendukung perkembangan Taman Pintar.

5. Lokasi tapak berada dalam jangkauan infrastruktur kota.

Berdasarkan dasar pertimbangan maka lokasi terpilih terletak di sisi Jalan Udayana. Gambar 1. menunjukkan kondisi eksisting tapak terpilih yang berbatasan pada sisi timur berupa Jalan Udayana dan permukiman, sisi barat berupa permukiman, serta pada sisi utara dan selatan yang berbatasan dengan persawahan. 


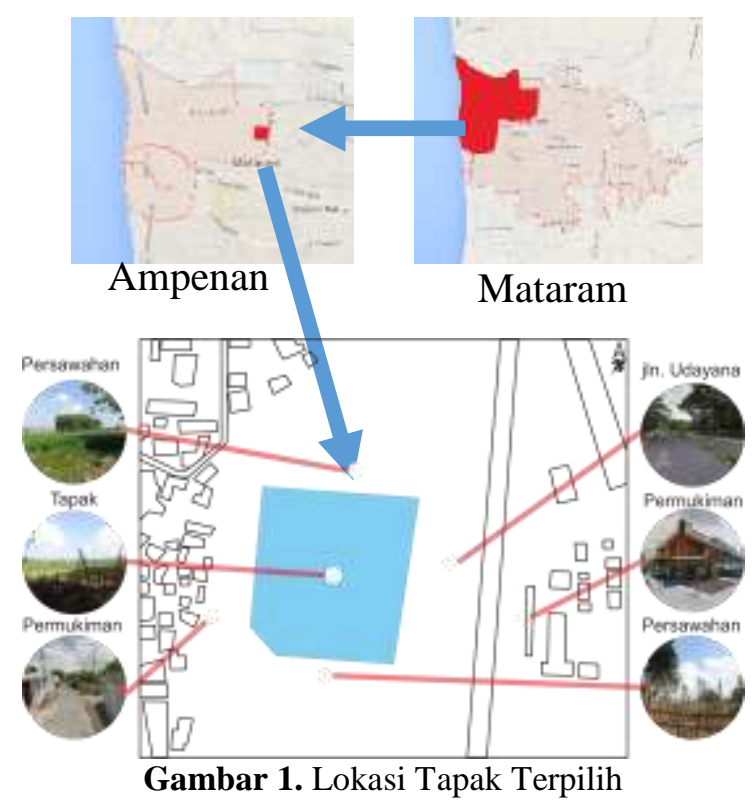

\subsection{Analisis Peruangan}

Analisis peruangan dilakukan dengan tujuan untuk mendapatkan peruangan yang sesuai dengan Taman Pintar. Dasar pertimbangan dalam analisis peruangan yaitu pengguna kegiatan dan kegiatan yang diwadahi.

Pengguna kegiatan pada Kawasan Taman Pintar terdiri dari pengunjung dan pengelola, sedangkan untuk kegiatan yang diwadahi terbagi menjadi:

1. Kegiatan Penerimaan

2. Kegiatan Utama

3. Kegiatan Penunjang

4. Kegiatan Pengelola

5. Kegiatan Servis

Tabel 1.Kebutuhan Ruang

\begin{tabular}{|l|l|l|}
\hline PENGGUNA & KEGIATAN & PERUANGAN \\
\hline \multirow{5}{*}{ Pengunjung } & Parkir & Area Parkir \\
\cline { 2 - 3 } & Datang & Hall Penerima \\
\cline { 2 - 3 } & $\begin{array}{l}\text { Menikmati } \\
\text { pameran }\end{array}$ & $\begin{array}{l}\text { R. Pameran } \\
\text { IPTEK }\end{array}$ \\
\cline { 2 - 3 } & \multirow{4}{*}{$\begin{array}{l}\text { Belajar dan } \\
\text { praktek }\end{array}$} & $\begin{array}{l}\text { R. Eksplorasi } \\
\text { sains }\end{array}$ \\
\cline { 2 - 3 } & $\begin{array}{l}\text { R. Eksplorasi } \\
\text { lingkungan }\end{array}$ \\
\cline { 2 - 3 } & \multirow{3}{*}{ Bermain } & $\begin{array}{l}\text { Area permainan } \\
\text { edukatif }\end{array}$ \\
\cline { 2 - 3 } & Area PAUD \\
\cline { 2 - 3 } & $\begin{array}{l}\text { Membaca } \\
\text { buku }\end{array}$ & R. Baca \\
\cline { 2 - 3 } & Menikmati & R. Serbaguna \\
\hline
\end{tabular}

\begin{tabular}{|l|l|l|}
\hline \multirow{5}{*}{} & $\begin{array}{l}\text { pertunjukan, } \\
\text { seminar dan } \\
\text { diskusi }\end{array}$ & \\
\cline { 2 - 3 } & Belanja & R. Komersial \\
\cline { 2 - 3 } & $\begin{array}{l}\text { Makan/minu } \\
\text { m }\end{array}$ & Foodcourt \\
\cline { 2 - 3 } & Ibadah & Masjid \\
\cline { 2 - 3 } & Metabolisme & Lavatory \\
\hline \multirow{5}{*}{ Pengelola } & Datang & Hall penerima \\
\cline { 2 - 3 } & \multirow{4}{*}{ Bekerja } & R. Informasi \\
\cline { 2 - 3 } & R. Pengelola \\
\cline { 2 - 3 } & Rapat & Rervis \\
\cline { 2 - 3 } & Parkir & Area Parkir \\
\cline { 2 - 3 } & Metabolisme & Lavatory \\
\cline { 2 - 3 } & $\begin{array}{l}\text { Makan/minu } \\
\text { m }\end{array}$ & Kantin \\
\hline
\end{tabular}

Pada Tabel 1. terlihat kebutuhan peruangan yang dibutuhkan pada kawasan Taman Pintar.

\subsection{Analisis Pencapaian}

Tujuan : lokasi main entrance dan side entrance pada tapak yang sesuai dengan kebutuhannya.

Dasar pertimbangan dalam menentukan main entrance yaitu :

1. Menghadap langsung ke jalan utama yang besar untuk memudahkan sirkulasi masuk dan keluar tapak

2. Mudah dikenali sebagai main entrance dan mudah dicapai.

3. Keamanan, kenyamanan dan kemudahan dalam pencapaian.

4. Mampu mengarahkan pengunjung ke dalam tapak

Dasar pertimbangan dalam menentukan side entrance yaitu :

1. Keamanan, kenyamanan dan kemudahan dalam pencapaian.

2. Menunjang fungsi main entrance.

3. Mendukung fungsi kegiatan bagi pengelola dan servis.

4. Tidak menggaggu sirkulasi kegiatan utama.

Kawasan Taman Pintar dilalui oleh dua jalan yaitu Jalan Udayana sebagai jalan kolektor primer dan Jalan Nusa Indah sebagai jalan perkampungan. 


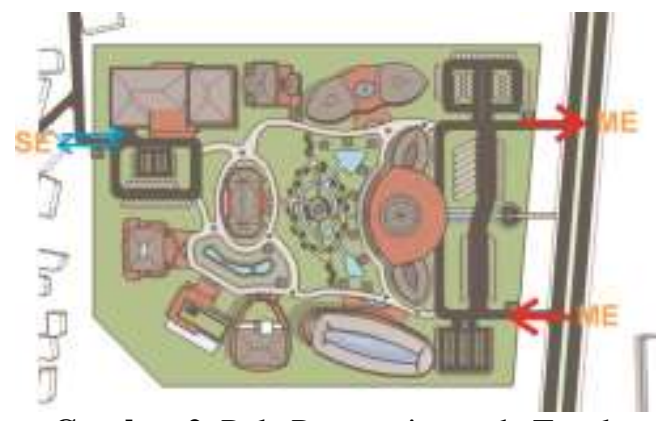

Gambar 2. Pola Pencapaian pada Tapak

Berdasarkan pada Gambar 2. main entrance diletakkan pada Jalan Udayana yang mudah dilihat, sedangkan side entrance diletakkan pada Jalan Nusa Indah agar tidak mengganggu pencapaian pengunjung

\subsection{Analisis Klimatologi}

Tujuan : kondisi iklim dan lingkungan yang terdapat di sekitar tapak, sebagai pertimbangan untuk menetukan orientasi, tata massa bangunan, pemilihan ruang serta pengkondisian ruang yang berpengaruh pada kebutuhan pencahayaan dan penghawaan alami.

Dasar pertimbangan dalam analisis klimatologis yaitu :

1. Kondisi eksisting tapak

2. Iklim pada tapak

3. Radiasi dan peredaran sinar matahari

4. Curah hujan, temperatur dan kelembaban

5. Arah pergerakan angin

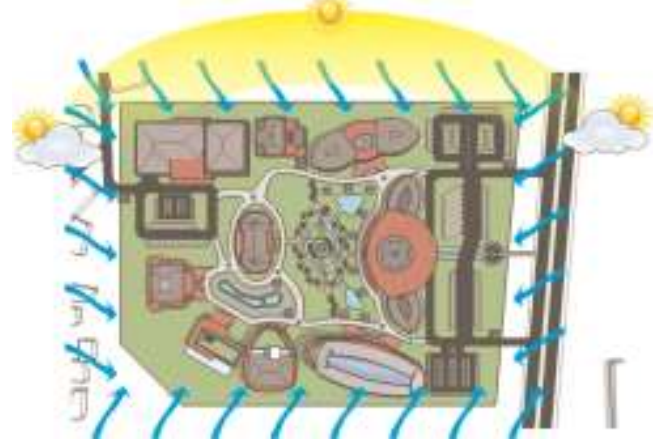

Gambar 3. Sirkulasi Angin dan Matahari pada Tapak
Kota Mataram terletak di daerah beriklim tropis, sehingga sinar matahari mempunyai intensitas menuju tapak sepanjang hari yang menjadi faktor pertimbangan dalam desain. Sedangkan untuk sirkulasi angin pada tapak, angin masuk menuju tapak dari berbagai arah.

Berdasarkan kondisi klimatologis pada tapak yang digambarkan pada Gambar 3. maka respon yang dapat diterapkan yaitu :

1. Sinar matahari dapat dimanfaatkan sebagai pencahayaaan alami dengan memaksimalkan bukaan pada bangunan.

2. Radiasi panas matahari dapat dimanfaatkan sebagai sumber energi alternatif.

3. Mengurangi silau dan panas matahari dengan memberikan barrier berupa vegetasi dan secondary skin.

4. Perletakan massa bangunan disesuaikan dengan sifat sinar yang dihasilkan matahari.

5. Angin yang berasal dari segala arah dapat dimanfaat sebagai penghawaan alami dengan memaksimalkan bukaan pada bangunan

6. Penyediaan barrier berupa vegetasi untuk menyesuaikan pergerakan angin sesuai dengan kebutuhan massa bangunan.

7. Angin yang membawa radiasi panas matahari direspon dengan pemberian unsur air untuk menghadirkan suasana sejuk pada kawasan.

8. Pemanfaatan angin menjadi energi alternatif

\subsection{Analisis Kebisingan}

Tujuan : tingkat kebisingan pada tapak yang akan menjadi bahan pertimbangan dalam pengolahan tapak dan penempatan massa bangunan pada tapak.

Dasar pertimbangan dalam analisis kebisingan yaitu intensitas sumber bising di sekitar tapak. Sumber bising utama pada tapak berasal dari bagian timur tapak yaitu Jalan Udayana sebagai jalan utama yang dilintasi oleh kendaraan bermotor. Pada sisi barat terdapat permukiman warga namun tingkat kebisingannya cukup rendah, sedangkan pada bagian utara dan selatan berbatasan persawahan dengan suasana sangat tenang. 


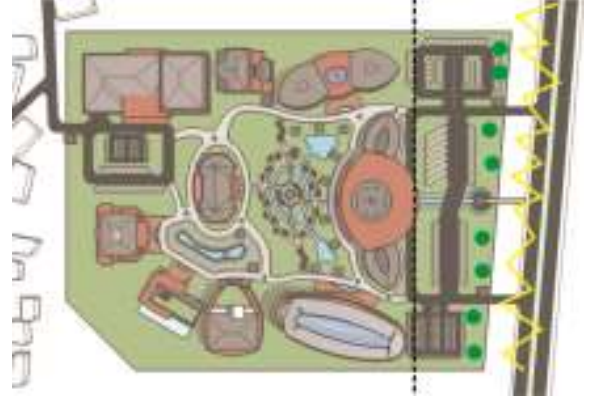

Gambar 4. Faktor Kebisingan dan Respon terhadap Tapak

Berdasarkan faktor kebisingan pada Gambar 4. maka respon untuk mengatasi kebisingan di sekitar tapak, yaitu :

1. Penggunaan barrier berupa vegetasi dan unsur air untuk memecah dan meredam kebisingan dari luar tapak.

2. Memberikan space/jarak dari sumber bising terhadap bangunan untuk mengurangi kebisingan.

\subsection{Analisis Pemintakatan (Penzoningan)}

Tujuan : tata letak massa pada bangunan Taman Pintar yang direncanakan. Sistem pemintakatan pada Kawasan Taman Pintar menyesuaikan dengan pengelompokan kegiatan yang telah dianalisis pada analisis kegiatan yang terdiri dari kegiatan penerimaan, kegiatan utama, kegiatan penunjang, kegiatan pengelola serta kegiatan servis.

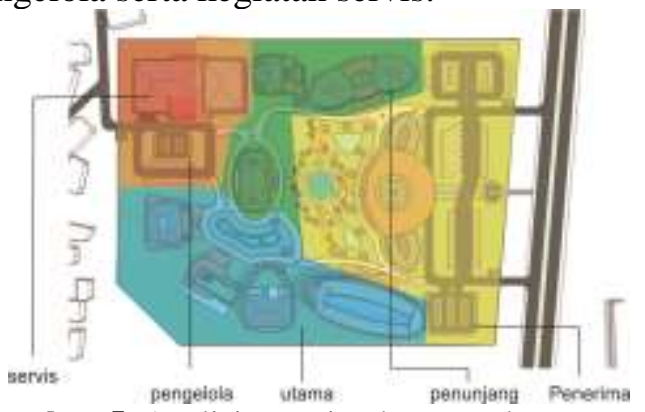

Gambar 5. Analisis Pemintakatan pada Kawasan Taman Pintar

Analisis pemintakatan berdasarkan pada Gambar 5. yaitu :

1. Bagian timur yang bersebelahan dengan Jalan Udayana digunakan untuk kegiatan penerimaan karena merupakan akses utama pengunjung (main entrance), sekaligus sebagai point of interest dari Taman Pintar.

2. Bagian barat berdekatan dengan Jalan Nusa Indah digunakan untuk kegiatan pengelola dan servis karena memiliki side entrance, sehingga tidak mengganggu kegiatan utama.

3. Bagian utara dan selatan dimanfaatkan untuk kegiatan utama dan penunjang yang mengoptimalkan penghawaan alami.

\subsection{Analisis Bentuk dan Tata Massa}

Tujuan : konsep massa yang sesuai dengan kegaitan yang terdapat pada Taman Pintar serta merespon kondisi pada tapak.

Bentuk dasar bangunan mempertimbangkan pengolahan gubahan massa bentuk lingkaran dan bujur sangkar dengan dasar pertimbangan

1. Karakteristik visual bentuk lingkaran sebagai bentuk dinamis dan bujur sangkar sebagai bentuk formal

2. Kemudahan dalam pengolahan gubahan massa

3. Fleksibilitas bentuk dan efisiensi penggunaan ruang.

4. Penyesuaian terhadap fisik di lingkungan tapak dan sekitar tapak.

5. Estetika bentuk.

Pengolahan bentuk lingkaran dan bujur sangkar ditransformasikan menjadi massa bangunan yang menyesuaikan dengan zona, fungsi dan kebutuhan ruang yang diwadahi.

Massa bangunan yang digunakan merupakan massa majemuk dengan pertimbangan Arsitektur Ekologi, yang memanfaatkan kondisi lingkungan tapak yang dapat meminimalkan penggunaan energi.

Penataan massa pada Kawasan Taman Pintar dapat dilihat pada Gambar 6. yang menerapkan tata massa dengan ruang sebagai pengikat massa majemuk.

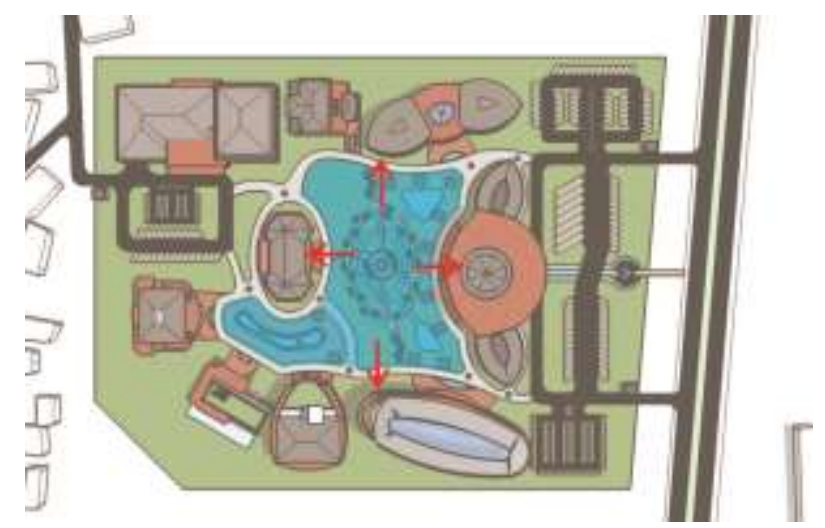

Gambar 6. Tata Massa pada Kawasan Taman Pintar 


\subsection{Analisis Sirkulasi}

Tujuan : pola sirkulasi pencapaian menuju tapak, antar massa bangunan dan antar ruang. Kriteria yang menjadi dasar pertimbangan yaitu :

1. Keamanan dan kenyamanan bagi para pengguna baik pejalan kaki maupun pengendara motor.

2. Efektif dan efisien agar tidak terjadi cross pada sirkulasi baik di dalam maupun di luar.

3. Kemudahan pencapaian antar massa bangunan.

4. Memberikan kebebasan gerak pada pengunjung sehingga pengunjung dapat bereksplorasi secara maksimal.

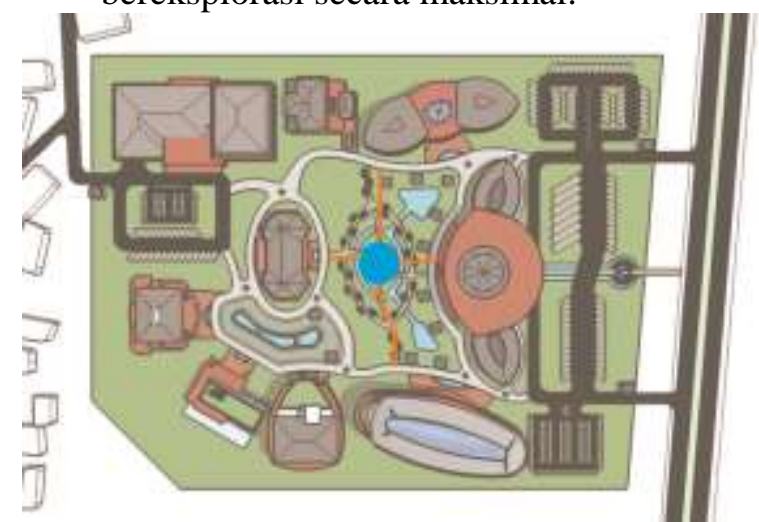

Gambar 7. Analisis Pola Sirkulasi Kawasan Taman Pintar

Pola sirkulasi pada Kawasan Taman Pintar seperti pada Gambar 7. menggunakan sistem sirkulasi radial, sedangkan untuk pola sirkulasi pada bangunan didominasi dengan sirkulasi linear. Pola sirkulasi linear dan radial digunakan, berdasarkan Ching (1996) memiliki karakteristik formal, informatif, mudah, terkoordinir serta rekreatif

\subsection{Analisis Material}

Tujuan : material yang akan diterapkan pada bangunan yang memperhatikan prinsip Arsitektur Ekologi serta kenyamanan pengguna bangunan.

Material yang digunakan yaitu :

Material pada kawasan lansekap mengkombinasikan material batu alam dan kayu

Material pada bangunan mengombinasikan material yang meminimalisir eksploitasi bahan alam, serta mempertimbangkan kenyamanan termal pada bangunan. Contoh : batu-bata, galvalum, baja ringan, zincalum serta beton

\subsection{Analisis Utilitas Pengolahan Air Kotor}

Tujuan : sistem pengolahan air kotor pada Taman Pintar sehingga dapat meminimalisir pencemaran terhadap lingkungan dan dapat digunakan kembali yang mengurangi penggunaan air dari PDAM. Dasar pertimbangan yaitu :

1. Perlindungan terhadap zat berbahaya

2. Konservasi air

3. Kemudahan dalam perawatan dan pengoperasian

Air kotor pada Kawasan Taman Pintar dibedakan berdasarkan sumber pembuangannya yang terbagi menjadi air buangan, air tinja dan air hujan.

Air kotor akan dialirkan menuju sistem pengolahan berupa sewage treatment plant. Air hasil pengolahan akan dimanfaatkan untuk penyiraman tanaman, flushing water pada toilet serta air untuk pemadam kebakaran. Sedangkan air tinja akan dialirkan menuju septic Tank kemudian menuju sumur peresapan.

\subsection{Analisis Utilitas Pengolahan Sampah}

Tujuan : sistem pengolahan sampah pada Taman Pintar sehingga dapat meminimalisir pencemaran terhadap lingkungan.

Dasar pertimbangan yaitu :

1. Jumlah/kapasitas sampah yang dihasilkan

2. Jenis sampah yang dihasilkan

3. Polusi yang ditimbulkan

4. Fasilitas lingkungan yang menunjang

Sampah-sampah yang dihasilkan pada Kawasan Taman Pintar terdiri dari sampah organik dan anorganik yang dipisahkan dengan penyediaan tempat sampah yang berbeda agar memudahkan dalam pengolahan, kemudian dikumpulkan pada area sampah sementara yang akan dipisahkan kembali antara sampah yang layak atau tidak untuk didaur ulang.

Sampah organik dapat dimanfaatkan sebagai pupuk dan sampah anorganik dijadikan barang-barang tepat guna, pemanfaatan ini akan berfungsi sebagai wahana pembelajaran bagi pengunjung Taman Pintar. Sampah yang tidak layak didaurulang akan dibawa menuju Tempat Pembuangan Akhir Kota Mataram.

\section{KESIMPULAN (KONSEP DESAIN)}

Taman Pintar dirancang untuk mewadahi kegiatan rekreasi edukasi mengenai ilmu pengetahuan dan teknologi, 
meningkatkan wawasan masyarakat, sebagai ruang publik dan mendukung pemerintah setempat.

Konsep rancangan Taman Pintar mengacu pada Arsitektur Ekologi yang terfokus pada adaptasi terhadap lingkungan dan konservasi unsur ekologi.

Aplikasi adaptasi lingkungan berupa gubahan dan tata massa pada rencana tapak yang dapat dilihat pada Lampiran dengan mempertimbangkan kondisi pada lingkungan seperti sirkulasi angin, radiasi dan sinar matahari serta kebisingan.

Rencana tapak juga memperlihatkan tata massa yang diterapkan pada Kawasan Taman Pintar menerapkan konsep ruang sebagai pengikat. pada :

Konservasi unsur ekologi diterapkan

- Air : pengolahan grey water menggunakan sistem sewage water treatment yang dapat dimanfaatkan kembali untuk menyiram tanaman, flushing water pada toilet serta air untuk pemadam kebakaran.

- Udara : penggunaan kisi-kisi serta ventilasi udara untuk mengoptimalkan penghawaan yang masuk pada bangunan yang dapat dilihat pada Gambar 8. dan Gambar 9. Ruang pada atap miring yang diterapkan pada tiap bangunan dimanfaatkan untuk pengkondisian udara. Penghawaan pada kawasan memanfaatkan peletakan massa, vegetasi serta elemen air yang dapat dilihat pada Lampiran 1.

- Tanah/material : material yang digunakan meminimalkan eksploitasi bahan alam. Pengolahan kembali limbah sampah yang layak daur ulang sehingga dapat menjadi materi edukasi kepada pengunjung. Konservasi tanah diaplikasikan dengan penyediaan ruang terbuka hijau pada kawasan.

- Api/energi : mengoptimalkan penghawaan dan pencahayaan alami sehingga meminimalisir penggunaan energi buatan. Memanfaatkan angin sebagai energi alternatif. Penerapan konsep massa majemuk sebagai bentuk efisiensi penggunaan energi.

Berdasarkan hasil analisa serta hasil korelasi dari beberapa data di atas, maka diperoleh hasil berupa rancangan Taman Pintar di Mataram sebagai berikut.
Nama Bangunan : Taman Pintar
Lokasi
: Jl. Udayana, Mataram
Luas Lahan
$: \pm 27.000 \mathrm{~m}^{2}$
Luas Bangunan
$: \pm 13.300 \mathrm{~m}^{2}$
Daya Tampung
$: \pm 1.500$ orang
Kegiatan
: Rekreasi Edukasi

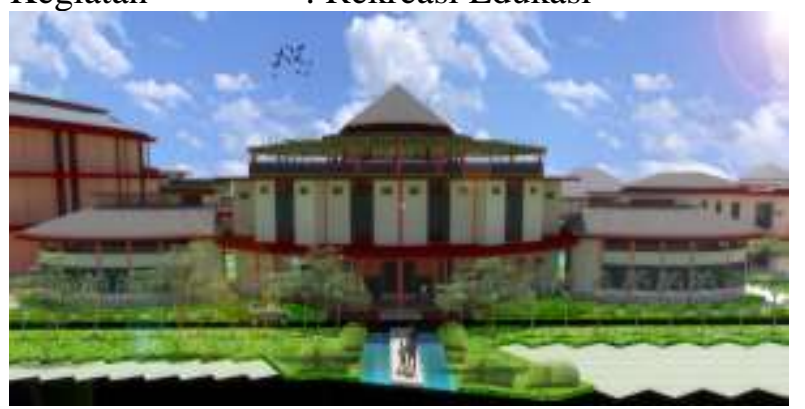

Gambar 8. Eksterior Bangunan Penerima

Aplikasi Arsitektur Ekologi pada bangunan yang ditunjukkan pada Gambar 8 . dan Gambar 9. terdiri dari :

- Penggunaan pergola pada atap datar yang berfungsi sebagai pengendali permasalahan pada lingkungan berupa radiasi matahari

- Penggunaan kisi-kisi sebagai secondary skin untuk mengoptimalkan angin masuk menuju bangunan sehingga dapat mendukung dalam konservasi energi

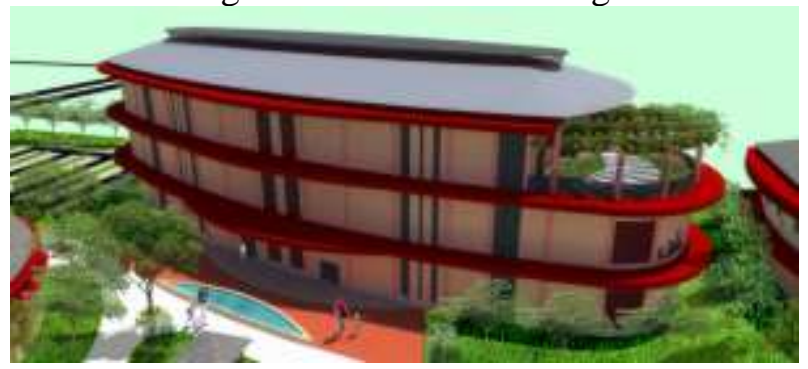

Gambar 9. Eksterior Bangunan Pameran Ilmu Pengetahuan dan Tekonologi

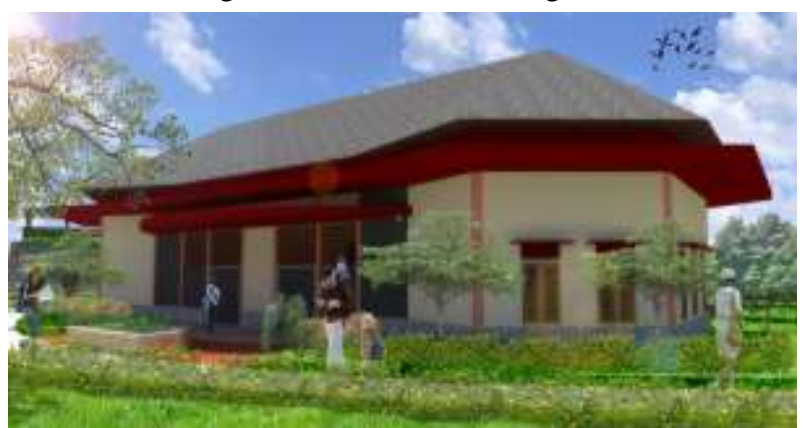

Gambar 10. Eksterior Area Baca/Perpustakaan

Gambar 10. menunjukkan pemanfaatan lansekap sebagai penambah nilai estetis, pengarah sirkulasi, peneduh, pengarah 
pemecah angin, peredam kebisingan serta penyerap polusi udara.

\section{REFERENSI}

Ching, Francis D,K. 1996, ARSITEKTUR :

Bentuk, Ruang, danTatanan. Edisi

Kedua. Cetakan Pertama. Terjemahan

Nurahma Tresani Harwadi. Jakarta :

Erlangga

Frick, Heinz \& Suskiyatno, Fx. Bambang. 1998, Dasar-dasar eko-arsitektur. Edisi ke-1. Yogyakarta: Yayasan Kanisius

Pemerintah Indonesia. 1945, Undang-Undang Republik Indonesia 1945

Pemerintah kota Mataram. 2011, Peraturan Daerah Kota Mataram no. 11 Tahun 2011 Tentang Rencana Pembangunan Jarak Menengah (RPJMD) Kota Mataram Tahun 2011-2015

Yuliani, Sri.2014, Metoda Perancangan Arsitektur Ekologi. Surakarta : Sebelas Maret University Press

mataram.antaranews.com (diakses pada 6 Februari 2015)

mataramkota.go.id (diakses 18 Juni 2015 pukul 19.45 WIB 
LAMPIRAN

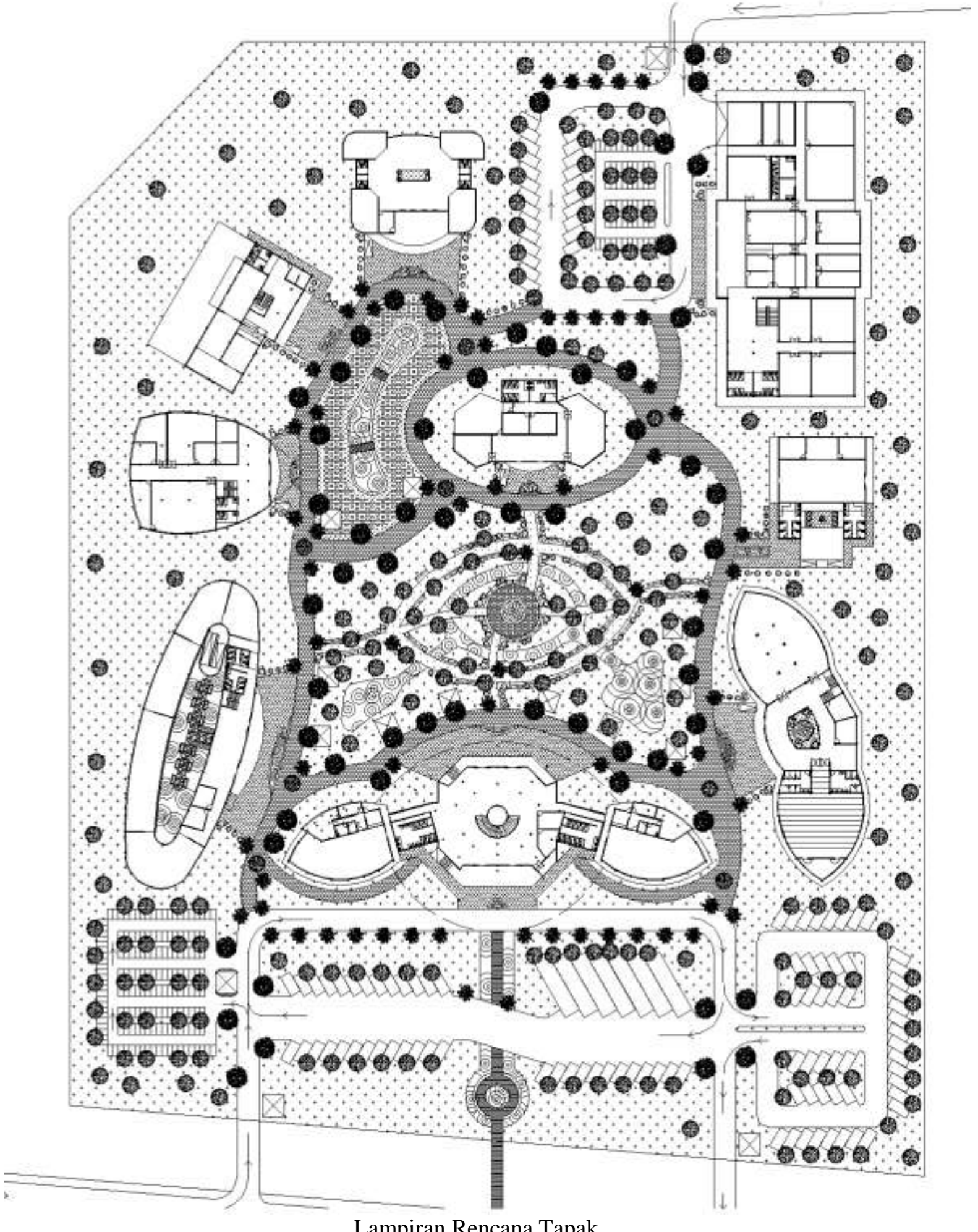

